\title{
Isoliquiritigenin, a Strong nod Gene- and Glyceollin Resistance- Inducing Flavonoid from Soybean Root Exudate
}

\author{
RÜDIGER KAPE, ${ }^{*}$ MARTIN PARNISKE, SEBASTIAN BRANDT, AND DIETRICH WERNER \\ Fachbereich Biologie, Philipps-Universität Marburg, Karl-von-Frisch-Strasse, D-3550 Marburg, Germany
}

Received 25 November 1991/Accepted 22 February 1992

\begin{abstract}
Isoflavonoid signal molecules from soybean (Glycine max (L.) Merr.) seed and root exudate induce the transcription of nodulation (nod) genes in Bradyrhizobium japonicum. In this study, a new compound with symbiotic activity was isolated from soybean root exudate. The isolated $2^{\prime}, 4^{\prime}, 4$-trihydroxychalcone (isoliquiritigenin) is characterized by its strong inducing activity for the nod genes of $B$. japonicum. These genes are already induced at concentrations 1 order of magnitude below those required of the previously described isoflavonoid inducers genistein and daidzein. Isoliquiritigenin is also a potent inducer of glyceollin resistance in $B$. japonicum, which renders this bacterium insensitive to potentially bactericidal concentrations of glyceollin, the phytoalexin of $G$. max. No chemotactic effect of isoliquiritigenin was observed. The highly efficient induction of nod genes and glyceollin resistance by isoliquiritigenin suggests the ecological significance of this compound, although it is not a major flavonoid constituent of the soybean root exudate in quantitative terms.
\end{abstract}

The interaction between legumes and bacteria of the genera Rhizobium and Bradyrhizobium results in the formation of nitrogen-fixing root nodules. One early event in this interaction is the induction of rhizobial nodulation genes (nod genes), which is mediated via the nodD gene product (for a review, see references 14 and 17). As a result of the nod gene induction, a nodulation factor (Nod factor) is produced by the bacterial symbiont, which in turn elicits root hair deformation, cortical cell devision, and nodule formation by the legume (32). Besides the well-characterized flavonoid inducers in all rhizobial systems (for a review, see references 17 and 29), further inducing compounds not belonging to this class of phenolic compounds have been identified by recent work; e.g., for Bradyrhizobium japonicum, a broad spectrum of diverse inducers was characterized $(4,13)$.

Analysis of soybean root exudate resulted in the identification of coumestrol and daidzein (5). In root extracts, genistein was found in addition to daidzein and coumestrol (25). All three compounds induce the nod genes of $B$. japonicum (15).

Besides the well-established nod gene-inducing activity of the flavonoids, further effects of these compounds on the microsymbiont are of symbiotic relevance (24). For fastgrowing rhizobia, e.g., Rhizobium meliloti (3), a chemotactic effect of flavonoids was found, while $B$. japonicum did not respond (13) or responded only very weakly (1) to isoflavonoids. The existence of a correlation between the nod gene-inducing and the chemotaxis-eliciting activities of the flavonoids and isoflavonoids was judged by these authors as being different for the different systems.

The list of the physiological effects of flavonoids on rhizobia is still growing, as exemplified by the discovery that the incubation of soybean-nodulating rhizobia $(B$. japonicum and Sinorhizobium fredii) in the presence of the isoflavone genistein or daidzein induced resistance to potentially bactericidal concentrations of glyceollin, the phytoalexin of soybean (22). This effect of isoflavonoids was found to be independent of nodD. Experiments dealing with phytoal-

\footnotetext{
* Corresponding author.
}

exin-containing root exudate suggest an important role of isoflavonoid-inducible glyceollin resistance for the survival of rhizobia in the rhizosphere of the soybean roots $(22)$.

The phytoalexin glyceollin is the final product of the pterocarpan biosynthetic pathway (9), which includes a number of compounds with functions in $B$. japonicumGlycine max symbiosis. This pathway starts with simple phenolic compounds which exhibit a strong chemotactic effect and a weak nod gene-inducing effect. Daidzein, a precursor of glyceollin (9), is a strong nod gene inducer but lacks any chemotactic activity (13). On the basis of knowledge of intermediates in this pathway, we aimed to find out whether other compounds participate in the communication between $B$. japonicum and $G$. max. 2',4',4-Trihydroxychalcone (isoliquiritigenin) is one of these intermediates. The objective of this study was to characterize the symbiotic activities and the ecological relevance of isoliquiritigenin. This chalcone was found in a number of legumes (for a review, see reference 34). Recently, Recourt et al. (26) identified it among other flavanones and chalcones in the root exudate of Vicia sativa subsp. nigra after inoculation with Rhizobium leguminosarum bv. viciae, but isoliquiritigenin has not yet been identified in soybean root exudate.

\section{MATERIALS AND METHODS}

Synthesis of isoliquiritigenin. Preliminary experiments were conducted with a sample of isoliquiritigenin which was kindly provided by E. Wollenweber (Darmstadt, Germany). Further experiments were performed with material synthesized in our laboratory.

Isoliquiritigenin was synthesized by aldol condensation of resacetophenone $\left(2^{\prime}, 4^{\prime}\right.$-dihydroxyacetophenone; Sigma, Munich, Germany) and 4-hydroxybenzaldehyde (Sigma) under nitrogen $(6,20,35)$. Both the ketone (resacetophenone) and the aldehyde (4-hydroxybenzaldehyde) were dissolved together in $15 \mathrm{ml}$ of ethanol at a concentration of $25 \mathrm{mM}$. Potassium hydroxide $(50 \mathrm{ml}$ of a $60 \%$ [wt/vol] solution) was added dropwise. The mixture was chilled in an ice bath to maintain the temperature below $4^{\circ} \mathrm{C}$. Afterwards, the reaction mixture was stirred for 2 more days under the exclusion of oxygen. Purification of isoliquiritigenin was accomplished 
by column chromatography on silica gel (Macherey-Nagel, Düren, Germany) (chloroform-methanol [94:6, vol/vol]) and polyamide (Roth, Karlsruhe, Germany) (methanol). The yield of crude product was $31.2 \%$ of the primary reactants. Recrystallization from methanol-water resulted in isoliquiritigenin with a melting point of $202^{\circ} \mathrm{C}\left(202\right.$ to $204^{\circ} \mathrm{C}$ [6]). A molecular mass of 256.073 for isoliquiritigenin was calculated. In mass spectroscopy, $m / e 256$ was found. The identity of the synthesized isoliquiritigenin was confirmed by ${ }^{1} \mathrm{H}$ NMR: $C_{3} \mathrm{OD} \delta 7.79\left(1 \mathrm{H}, \mathrm{d}, J_{\alpha, \beta}=16 \mathrm{~Hz}, \mathrm{H}_{\alpha}\right), 7.61(1 \mathrm{H}, \mathrm{d}$, $\left.J_{\beta, \alpha}=16 \mathrm{~Hz}, \mathrm{H}_{\beta}\right), 7.62(2 \mathrm{H}, \mathrm{dt}, J=9 \mathrm{~Hz}, 2$ and $6 \mathrm{H}), 6.88$ $(2 \mathrm{H}, \mathrm{dt}, J=9 \mathrm{~Hz}, 3$ and $5 \mathrm{H}), 7.98\left(1 \mathrm{H}, \mathrm{d}, J_{6^{\prime}, 5^{\prime}}=9 \mathrm{~Hz}\right.$, $\left.6^{\prime} \mathrm{H}\right), 6.42\left(1 \mathrm{H}, \mathrm{dd}, J_{5^{\prime}, 6^{\prime}}=9 \mathrm{~Hz}, J_{5^{\prime}, 3^{\prime}}=3 \mathrm{~Hz}, 5^{\prime} \mathrm{H}\right), 6.29$ $\left(1 \mathrm{H}, \mathrm{d}, J_{3^{\prime}, 5^{\prime}}=3 \mathrm{~Hz}, 3^{\prime} \mathrm{H}\right),\left(\mathrm{CD}_{3}\right)_{2}$ SO $\delta 3.39(1 \mathrm{H}, \mathrm{s}, 4 \mathrm{OH})$, $10.41\left(1 \mathrm{H}, \mathrm{s}, 4^{\prime} \mathrm{OH}\right), 13.63\left(1 \mathrm{H}, \mathrm{s}, 2^{\prime} \mathrm{OH}\right)$.

Preparation of soybean root exudate. Soybean seeds $(G$. $\max ($ L.) Merr. cv. Maple Arrow) were washed with water and afterwards surface sterilized for $10 \mathrm{~min}$ in $30 \%$ hydrogen peroxide plus some drops of Tween 20 (polyoxyethene sorbitan monolaurate; Serva, Heidelberg, Germany). After sterilization, seeds were washed 10 times, and afterwards they imbibed sterile tap water for $7 \mathrm{~h}$ on a shaker $(100 \mathrm{rpm})$ at $28^{\circ} \mathrm{C}$. The water was changed twice during this procedure to remove seed-derived compounds. After soaking, seeds were again rinsed thoroughly with sterile water and grown in sterile Perlite-Vermiculite $(1: 2)$ for $65 \mathrm{~h}$ in a growth cabinet $\left(25^{\circ} \mathrm{C}\right.$; relative humidity, $75 \%$; $16-8 \mathrm{~h}$ light-dark period, irradiance, $13 \mathrm{~W} \mathrm{~m}^{-2}$ ). Then the seedlings were individually transferred onto a stainless-steel lattice which was placed in a glass petri dish (diameter, $22 \mathrm{~cm}$; height, $7 \mathrm{~cm}$ ). The roots of the seedlings grew through the holes of the lattice and along the surface of a cellulose acetate filter (diameter, 203 mm, type OE66; Schleicher and Schuell $\mathrm{GmbH}$, Dassel, Germany) at the bottom of the petri dish $1 \mathrm{~cm}$ below the lattice. The filter was moistened with MES [2- $(N$-morpholino)ethanesulfonic acid] buffer ( $5 \mathrm{mM}, \mathrm{pH} 6.2$ ) (Serva) plus $\mathrm{CaCl}_{2}(1 \mathrm{mM})\left(\mathrm{MES}-\mathrm{CaCl}_{2}\right)$. The cellulose acetate filter absorbs the flavonoids exuded by the root (27). After 4 days, the filter was rinsed three times with distilled water to remove all easily water-soluble compounds and cell debris. Flavonoids were extracted with three washes of methanol. After filtration (glass fiber filter, Whatman GF/C), the crude extract was stored at $-20^{\circ} \mathrm{C}$ in the dark. It was used for analytical studies and the preparation of isoliquiritigenin.

Preparation of soybean seed exudate. Soybean seed exudate was produced as follows. Seeds were washed and sterilized as described above for the preparation of root exudate. Seeds were then placed on sterile cellulose acetate filters moistened with $\mathrm{MES}-\mathrm{CaCl}_{2}$ for $24 \mathrm{~h}$. Flavonoid preparation was performed as described above for the root exudate.

Analytical methods. (i) HPLC. High-pressure liquid chromatography (HPLC) was performed on an RP 18 (Octadecyl) $10-\mu \mathrm{m}$ column ( 250 by $4.6 \mathrm{~mm}$ ) (Serva). The following gradient was used for the separation of isoliquiritigenin from compounds with similar retention behavior at a flow rate of $1 \mathrm{ml} / \mathrm{min}$ : 27 to $32 \%$ solvent $\mathrm{B}$ (acetonitrile) within $50 \mathrm{~min}$; solvent $\mathrm{A}$, water acidified to $\mathrm{pH} 3$ with acetic acid. Eluting compounds were detected with a variable-wavelength detector at 250 or $368 \mathrm{~nm}$ (absorption maximum of isoliquiritigenin). For further analytical and biological studies, fractions of several HPLC runs containing the putative isoliquiritigenin were pooled and dried under vacuum. These pooled fractions will be termed the isoliquiritigenin fraction. Flavonoid compounds of the soybean root exudate which have already been described in the literature (daidzein, genistein, and coumestrol) were identified by cochromatography with authentic standards.

(ii) TLC. Thin layer chromatography (TLC) was executed on nano plates (Sil-20 UV254) (10 by $10 \mathrm{~cm}$ ) (MachereyNagel). The best separation of the isoflavonoids was obtained with toluene-ethylacetate-methanol (70:25:5, vol/vol/ vol). TLC plates were evaluated with a Desaga CD60 densitometer (Desaga, Heidelberg, Germany), which allows UV-visible absorption spectra of single spots on TLC plates.

(iii) GC-MS. For gas chromatography-mass spectroscopy (GC-MS) analysis, a Varian 3400 in combination with an Ion Trap Detector ITD 800 (Finnigan MAT, Bremen, Germany) was used. The separation was accomplished on a DB-1 column $(30 \mathrm{~m})(\mathrm{J} \& \mathrm{~W}$ Scientific) with the following temperature program: 220 to $280^{\circ} \mathrm{C}$ at $2^{\circ} \mathrm{C} / \mathrm{min}$, after an initial delay of $1 \mathrm{~min}$. The final column temperature was held for $15 \mathrm{~min}$. Samples were purified by HPLC before they were analyzed by GC-MS. These purified samples were dried under vacuum and stored until derivatization over silica gel. The dry samples were taken up in $99 \%$ bis(trimethylsilyl)trifluoroacetamide-1\% trimethylchlorosilane (Sigma) and incubated at $60^{\circ} \mathrm{C}$ for $15 \mathrm{~h}$ to obtain the trimethylsilyl derivatives of the flavonoids.

Biological activities of isoliquiritigenin. (i) Chemotaxis. The chemotaxis assay was performed essentially as described previously (13). The following modifications were introduced. B. japonicum $110 s p c 4$ (28) was cultured in the complex medium 20E (33) supplemented with MES $(20 \mathrm{mM}$, $\mathrm{pH} 6.5)$ (20E-MES). Cultures were incubated at $28^{\circ} \mathrm{C}$ on a rotary shaker $(100 \mathrm{rpm})$. Isoliquiritigenin was tested at concentrations from $10^{-4}$ to $10^{-10} \mathrm{M}$. Caffeic acid, a strong chemoattractant (13) of $B$. japonicum, was used as a positive control. Chemotactic activity was expressed as the chemotactic ratio (the number of bacteria attracted by the test substance divided by the number of bacteria in the buffer control).

(ii) Induction of nod genes. The assay of nod gene induction was performed according to Kape et al. (13). The following changes were introduced. B. japonicum $110 s p c 4$ harboring plasmid pRJ458 (7) was grown in 20E-MES. Cultures were incubated at $28^{\circ} \mathrm{C}$ on a rotary shaker $(100 \mathrm{rpm})$ for $15 \mathrm{~h}$ in the presence of varying concentrations of the test compounds $\left(10^{-4}\right.$ to $\left.10^{-10} \mathrm{M}\right)$. For nod gene induction tests with isoliquiritigenin isolated from root exudate, the culture volume was reduced to $0.5 \mathrm{ml}$. Cells were grown in $2-\mathrm{ml}$ glass vials with Teflon-lined screw caps (Renner GmbH, Dannstadt, Germany).

(iii) Induction of glyceollin resistance. The glyceollin resistance induction assay was conducted as described previously (22). In short, the rhizobial strain (here, B. japonicum 110 spc 4 harboring plasmid pRJ458) was cultured in a complex medium in the presence of the test compound (here, $10^{-5} \mathrm{M}$ isoliquiritigenin). After $15 \mathrm{~h}$, an aliquot of this culture was transferred to MES buffer ( $5 \mathrm{mM}, \mathrm{pH} 6.5$ ) containing glyceollin $\left(3 \times 10^{-4} \mathrm{M}\right)$. After $3 \mathrm{~h}$ of incubation in this phytoalexin solution, the appropriate dilutions were plated on $20 \mathrm{E}$ agar to estimate the number of surviving CFU. Glyceollin resistance is expressed as the percentage of cells that survived the incubation in glyceollin.

Comparison of the symbiotic effects of the intermediates of the pterocarpan biosynthetic pathway. nod gene induction and induction of glyceollin resistance by intermediates of the pterocarpan biosynthetic pathway and side branches of this pathway were tested together as follows. B. japonicum $110 s p c 4$ harboring pRJ458 was cultured in 20E-MES as described for the nod gene induction assay in the presence of 


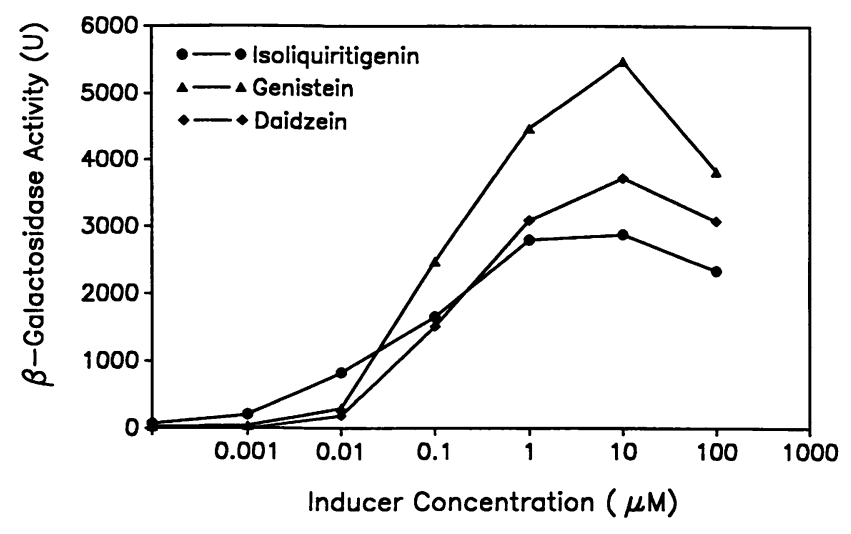

FIG. 1. Induction of $B$. japonicum nod genes by isoliquiritigenin, genistein, and daidzein. Compounds were tested for their abilities to induce transcription of $\beta$-galactosidase from $B$. japonicum $110 s p c 4$ harboring plasmid pRJ458 (nodC-lacZ). The background level of $\beta$-galactosidase activity was subtracted.

the test compounds $\left(10^{-5} \mathrm{M}\right)$. After $15 \mathrm{~h}$, samples of these cultures were tested for nod gene induction and induction of glyceollin resistance. Chemotaxis data presented in this study, except those for isoliquiritigenin, were taken from Kape et al. (13).

\section{RESULTS}

Biological activity of isoliquiritigenin. (i) Induction of nod genes. Isoliquiritigenin was identified as a strong nod gene inducer. This induction was compared to that of other nod gene inducers (Fig. 1). Isoliquiritigenin exhibited an inducing activity already at $1 \mathrm{nM}$. This concentration is about 1 order of magnitude below those required of the previously described strong nod gene inducers daidzein and genistein. The stronger nod gene-inducing activity of isoliquiritigenin at extremely low concentrations is in contrast to its reduced inducing activity at higher concentrations; the opposite is true for daidzein or genistein. The maximal nod gene induction of all three compounds was achieved at a concentration of $10 \mu \mathrm{M}$. The concentrations required for half-maximum activities of nod gene induction were 52,144 , and $159 \mu \mathrm{M}$ for isoliquiritigenin, daidzein, and genistein, respectively (mean values of two experiments).

(ii) Chemotactic effect of isoliquiritigenin. No chemotactic effect of isoliquiritigenin could be detected, while the positive control, caffeic acid, caused a strong chemotactic response. A chemotactic ratio of 31 was obtained for caffeic acid at a concentration of $10 \mathrm{mM}$ (mean value of three independent experiments).

(iii) Induction of glyceollin resistance. Isoliquiritigenin proved to be a strong inducer of glyceollin resistance in $B$. japonicum $110 s p c 4$ harboring pRJ458. As depicted in Fig. 3, the applied concentration of $10 \mu \mathrm{M}$ resulted in a resistance of $90 \%$ of all cells in the test culture against a glyceollin concentration of $300 \mu \mathrm{M}$. The degree of resistance is as high as that obtained by genistein, the best inducer of glyceollin resistance described up to now (22).

Detection of isoliquiritigenin in soybean root exudate. The applied system for cultivation of soybean seedlings allows fast preparation of the root exudate flavonoid fraction without any contaminations from the seed exudate flavonoid fraction. The following experimental evidence proves the presence of isoliquiritigenin in this root exudate flavonoid fraction.
HPLC analysis with peak detection at $250 \mathrm{~nm}$ allowed the identification of the major flavonoid compounds in the root exudate, namely, daidzein (retention time, $11.3 \mathrm{~min}$ ), genistein (retention time, $21.8 \mathrm{~min}$ ), and coumestrol (retention time, $23.2 \mathrm{~min}$ ). Peak detection at $368 \mathrm{~nm}$, the maximum absorption of isoliquiritigenin, and cochromatography with the authentic standard (retention time, $34.4 \mathrm{~min}$ ) provided strong evidence for the presence of this chalcone in the root exudate. Figure 2 illustrates the HPLC separation with detection at both wavelengths. The HPLC fraction containing the putative isoliquiritigenin was submitted to further testing by using analytical methods.

GC-MS analysis exhibited identical retention times for the trimethylsilyl derivatives of the main constituent in the isoliquiritigenin fraction and the authentic standard (retention time, $22 \mathrm{~min}$ ). The calculated molecular mass of the trimethylsilyl derivative of isoliquiritigenin is 472.19 . The $m / e \mathbf{4 7 2}$ was found for the authentic standard as well as for the main component of the isoliquiritigenin fraction. In both spectra, the base peak was $m / e$ 458. These consistent data for the authentic standard and the isolated sample are strong arguments for their identity.

A separation of the isoliquiritigenin fraction on thin-layer plates resulted in a main spot with an $R_{f}$ value of 0.48 , identical to that for the authentic standard. The UV-visible spectra (200 to $600 \mathrm{~nm}$ ) of these spots were almost identical, with absorption maxima at $378 \mathrm{~nm}$. Minor differences occurred in the short wavelength area which were probably due to overlying contaminating substances from the root exudate.

Further important confirming evidence that the main component of the isoliquiritigenin fraction is in fact isoliquiritigenin came from the nod gene induction assay. Both the authentic standard and the isoliquiritigenin fraction, adjusted to the same $A_{368}$, exhibited almost identical concentration dependence curves of nod gene induction, with the typical onset of nod gene induction at concentrations below $10 \mathrm{nM}$.

A quantitative analysis of the identified nod gene inducers in soybean root exudate by HPLC resulted in concentration ratios for daidzein-genistein-coumestrol-isoliquiritigenin of 28.6:2.3:3.3:1. There was hardly any variation in this ratio for three separate seedling cultivations. Hence, daidzein is the quantitatively dominant nod gene inducer in the exudate.

Composition of soybean seed exudate. HPLC analysis of soybean seed exudate resulted in the detection of high quantities of daidzein and genistein, while isoliquiritigenin and coumestrol were missing in the seed exudate.

Comparison of the symbiotic activities of intermediates of the pterocarpan biosynthetic pathway. Figure 3 summarizes the effects of the intermediates of the pterocarpan pathway and its side branches on $B$. japonicum. Striking differences between the individual intermediates in relation to their symbiotic effects are apparent. While only simple phenolic acids are strong chemoattractants for $B$. japonicum, these compounds exhibit no induction of glyceollin resistance and nod genes or are only weak nod gene inducers. The chalcone isoliquiritigenin and the isoflavone daidzein (as well as genistein on a parallel biosynthetic pathway) are strong inducers of nod genes and glyceollin resistance, while the more complex isoflavonoids, glycinol and glyceollin, are less potent symbiotic signals. It is noteworthy that there is no complete correlation between the two inducing activities of the intermediates. While daidzein, genistein, and isoliquiritigenin are both strong nod gene inducers and inducers of glyceollin resistance, coumestrol, for example, induces nod genes but not glyceollin resistance. 


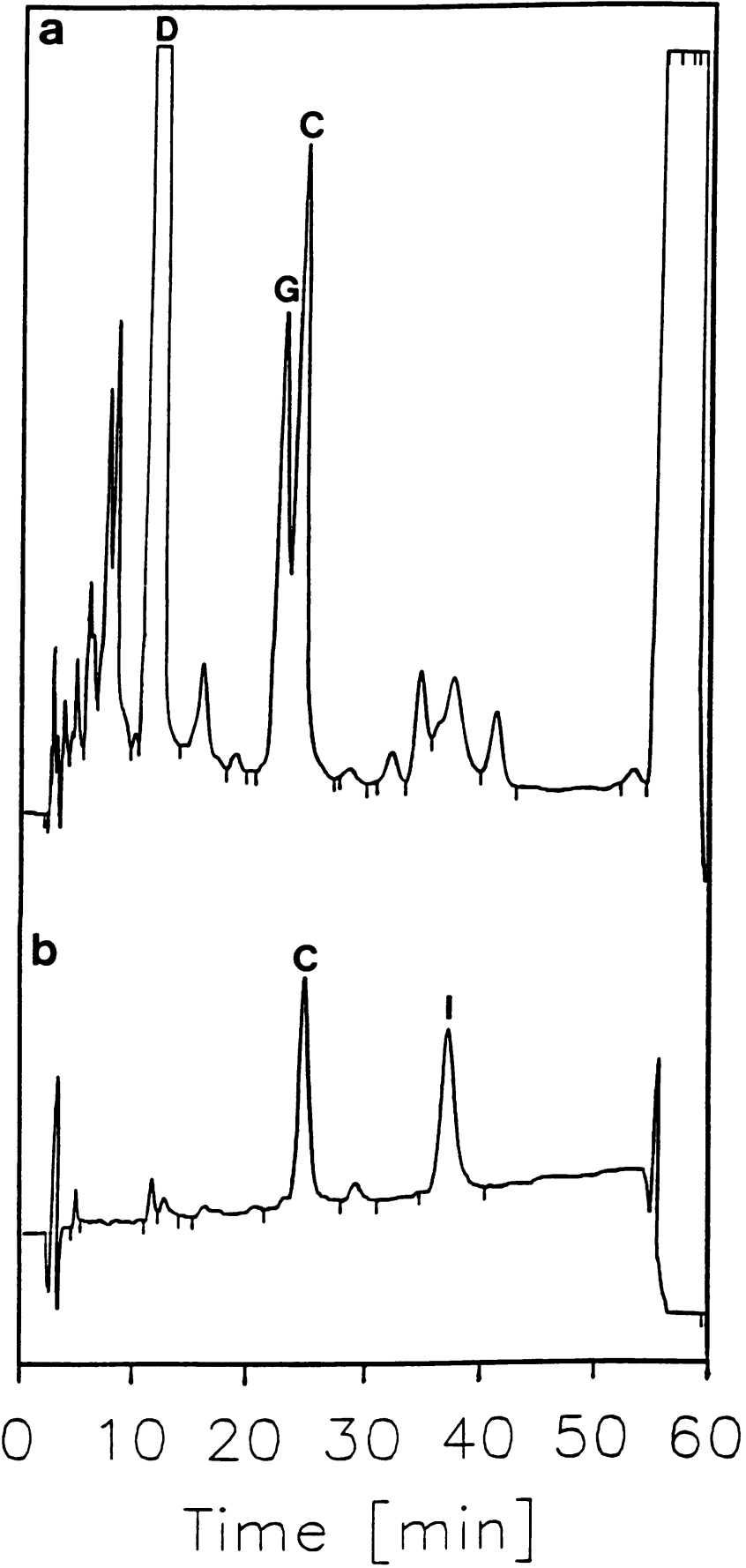

FIG. 2. HPLC profiles of soybean root exudate. UV detection levels at $250 \mathrm{~nm}$ (a) and $368 \mathrm{~nm}$ (b) are indicated. D, daidzein; G, genistein; C, coumestrol; i, isoliquiritigenin.

\section{DISCUSSION}

The results presented here prove that isoliquiritigenin, a component of soybean root exudate, has strong symbiotic activity. nod gene induction at very low concentrations and strong induction of glyceollin resistance are the most striking symbiotic features of this compound, which strongly supports a physiological relevance for $B$. japonicum and $G$. max symbiosis. No chemotactic activity of $B$. japonicum in response to isoliquiritigenin was found.

It is important that isoliquiritigenin, a chalcone, is structurally less complex than the strong isoflavonoid nod gene inducers for $B$. japonicum described up to now. This finding in connection with those of recently published studies illustrates the broad spectrum of potential nod gene inducers for $B$. japonicum. This broad spectrum includes simple phenolic compounds (13) as well as complex flavonoids and isoflavonoids $(4,15)$. To date, this large diversity of inducing compounds is known only for the broad-host-range rhizobia Rhizobium spp. NGR234 and MPIK3030 (2, 11, 16).

The importance of chalcones for Rhizobium-legume interaction was recently demonstrated with the $R$. meliloti-alfalfa system (18). In alfalfa root exudate, isoliquiritigenin was missing, but its $2^{\prime}$-methoxy derivative was present. Both chalcones are nod gene inducers of $R$. meliloti nod genes. 4,4'Dihydroxy-2'-methoxychalcone, the stronger inducer of both compounds in $R$. meliloti, is a major component of alfalfa root exudate. This chalcone induced $R$. meliloti nod genes at a concentration 1 order of magnitude lower than luteolin, a flavone (18). Therefore, the nod gene-inducing behavior of this alfalfa chalcone is comparable to that of isoliquiritigenin in the soybean root exudate. In both cases, the chalcone seems to be the most effective nod gene inducer characterized so far. The reason for the increased nod gene-inducing efficiency of isoliquiritigenin in comparison to that of isoflavonoids is unknown. One possible explanation is an enhanced accessibility of the putative site of action in the plasma membrane (30) by isoliquiritigenin through the outer membrane. This speculation is supported by the water solubility of isoliquiritigenin, which is better than that of the isoflavonoids. There is one remarkable difference between the nod gene induction behavior of $4,4^{\prime}$-dihydroxy-2'-methoxychalcone in $R$. meliloti and that of isoliquiritigenin in B. japonicum. While the alfalfa chalcone produces a maximal nod gene induction which is higher than those of the other major inducers, nod gene induction by isoliquiritigenin does not reach the maximum induction levels obtained by isoflavonoids. A further similarity between the alfalfa chalcone and isoliquiritigenin in soybean in addition to the high efficiency of nod gene induction is apparent. Both chalcones are constituents of the root exudates but are not present in seed exudates $(18,24)$.

The biological importance of the highly effective isoliquiritigenin, which is present only in low concentrations in the root exudate, is difficult to estimate and has to be evaluated in connection with those of other phenolic compounds with symbiotic activity. As depicted in Fig. 3, effects on $B$. japonicum are not restricted to isoflavonoids. Simple phenolic compounds are chemoattractants but lack the ability to induce glyceollin resistance and nod genes or are only weak nod gene inducers. The isoflavonoids are not chemoattractants but are strong inducers of glyceollin resistance and of nod genes. The different intermediates in the same biosynthetic pathway may be assigned special functions for symbiosis. It remains to be elucidated whether the legume makes use of the multiple functions exhibited by these compounds to manipulate the rhizobial soil population. An active use of this array of substances would be possible only in the case of a spatial regulation of the exudation along the root. Certain local areas of the root would then be characterized by a certain set of exuded compounds and a certain influence on the microsymbiotic partner. First results argue in favor of such a complex spatial regulation of exudation. Gulash et al. (10) observed the attraction of $R$. meliloti cells to localized spots on the root surface of the infectible region of alfalfa 


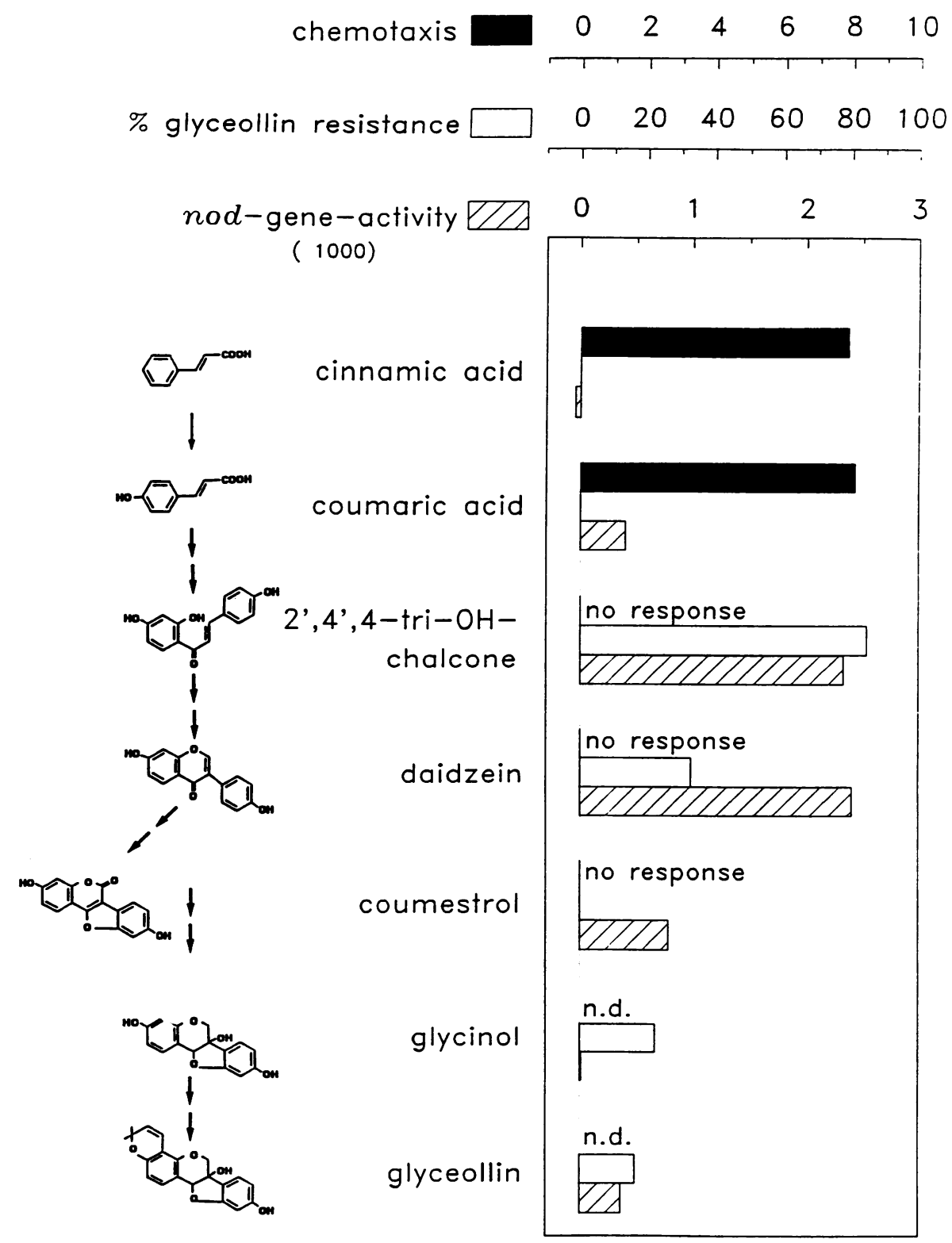

FIG. 3. Differential inductions of symbiotic activities in $B$. japonicum by intermediates of the pterocarpan and the coumestan biosynthetic pathways. Glyceollin resistance data and nod gene activation data are from one experiment. Test compounds were applied at a concentration of $10 \mu \mathrm{M}$. nod gene activity is expressed in $\beta$-galactosidase units (in thousands) (according to reference 19). Glyceollin resistance is expressed as the percentage of cells that survived a 3-h incubation in $300 \mu \mathrm{M}$ glyceollin. The chemotaxis data, except those for isoliquiritigenin, are derived from Kape et al. (13) and are expressed as the chemotactic ratio at the concentration which elicited the chemotactic peak response. n.d., not determined. (Figure 3 is taken from reference 21.)

roots. By using a plate induction assay, Peters and Long (23) demonstrated that the inducers of $R$. meliloti nod genes are exuded from the infectible zone of the root. Graham (8) found distinct differences in the flavonoid-isoflavonoid composition of soybean seedling organs in dependence of the developmental state and the light regime. He elucidated differences in the isoflavonoid contents of individual root segments. Autofluorescence photographs of the soybean root suggest local differences in isoflavonoid concentrations (21). The response of $B$. japonicum to the exuded compounds seems to be dependent on different signal-transducing systems. A chemotactic attraction is the only strong response elicited by simple phenolic acids; therefore, a separate signal transduction system has to be postulated for the chemotactic response. nod gene induction and induction of glyceollin resistance have different sets of inducers; e.g., coumestrol, a major component of the root exudate, induces nod gene activity but not glyceollin resistance. The induction of glyceollin resistance is also independent of the nodD gene product. For these reasons, different mechanisms seem to be inherent to these induction processes. The separate induction processes enable $B$. japonicum to respond differently to individual compounds in the bacterial environment.

The complex spatial regulation of flavonoid exudation into the rhizosphere is not static but highly dynamic. Multiple factors, e.g., the developmental state (23), the presence of 
pathogens which may elicit phytoalexin exudation (31), inoculation with rhizobia (26), and abiotic factors (e.g., light [8]) influence the root exudation. Additionally, already exuded substances are subjected to changes by biotic and abiotic factors. Rhizobial as well as legume-derived enzymes modify exuded compounds $(8,12)$.

When all of its elements are taken together, the rhizosphere seems to be a highly diverse and dynamic space with complex interactions among all inhabiting organisms. The investigation of this complex system is certainly an important step toward the understanding of Rhizobium species and legume symbiosis.

\section{ACKNOWLEDGMENTS}

We thank M. Göttfert (ETH-Zürich, Switzerland) for providing $B$. japonicum 110spc4 harboring plasmid pRJ458 and E. Wollenweber (Darmstadt, Germany) for a sample of isoliquiritigenin.

We also thank the Bundesminister für Forschung und Technologie (Bonn). The project on which this report is based was supported by funds from the BMFT under agreement 0318966B.

\section{REFERENCES}

1. Barbour, W. M., D. R. Hattermann, and G. Stacey. 1991. Chemotaxis of Bradyrhizobium japonicum to soybean exudates. Appl. Environ. Microbiol. 57:2635-2639.

2. Broughton, W. J., A. Krause, A. Lewin, X. Perret, N. P. J. Price, B. Relic, P. Rouchepau, C.-H. Wong, S. G. Pueppke, and S. Brenner. 1991. Signal exchange mediates host-specific nodulation of tropical legumes by the broad host-range Rhizobium species NGR234, p. 162-167. In H. Hennecke and D. P. S. Verma (ed.), Advances in molecular genetics of plant-microbe interactions, vol. 1. Kluwer Academic Publishers, The Netherlands.

3. Caetano-Anollés, G., D. K. Crist-Estes, and W. D. Bauer. 1988. Chemotaxis of Rhizobium meliloti to the plant flavone luteolin requires functional nodulation genes. J. Bacteriol. 170:3164-3169.

4. Cunningham, S., W. D. Kollmeyer, and G. Stacey. 1991. Chemical control of interstrain competition for soybean nodulation by Bradyrhizobium japonicum. Appl. Environ. Microbiol. 57:18861892.

5. D'Arcy-Lameta, A. 1986. Study of soybean and lentil root exudates. II. Identification of some polyphenolic compounds, relation with plantlet physiology. Plant Soil 92:113-123.

6. Geissman, T. A., and R. O. Clinton. 1946. Flavanones and related compounds. I. The preparation of polyhydroxychalcones and -flavanones. J. Am. Chem. Soc. 68:697-700.

7. Göttfert, M., S. Hitz, and H. Hennecke. 1990. Identification of $\operatorname{nod} S$ and nodU, two inducible genes inserted between the Bradyrhizobium japonicum nodYABC and nodIJ genes. Mol. Plant-Microbe Interact. 3:308-316.

8. Graham, T. L. 1991. Flavonoid and isoflavonoid distribution in developing soybean seedling tissues and in seed and root exudates. Plant Physiol. 95:594-603.

9. Grisebach, H., L. Edelman, D. Fischer, G. Kochs, and R. Welle. 1989. Biosynthesis of phytoalexins and nod-gene inducing isoflavones in soybean, p. 57-64. In B. J. J. Lugtenberg (ed.), Signal molecules in plant and plant-microbe interactions. NATO ASI Series, vol. H 36. Springer-Verlag, Berlin.

10. Gulash, M., P. Ames, R. C. Larosiliere, and K. Bergman. 1984. Rhizobia are attracted to localized sites on legume roots. Appl. Environ. Microbiol. 48:149-152.

11. Györgypal, Z., E. Kondorosi, and A. Kondorosi. 1991. Diverse signal sensitivity of NodD protein homologs from narrow and broad host range rhizobia. Mol. Plant-Microbe Interact. 4:356-364.

12. Hartwig, U. A., and D. A. Phillips. 1991. Release and modification of nod-gene-inducing flavonoids from alfalfa seeds. Plant Physiol. 95:804-807.

13. Kape, R., M. Parniske, and D. Werner. 1991. Chemotaxis and nod gene activity of Bradyrhizobium japonicum in response to hydroxycinnamic acids and isoflavonoids. Appl. Environ. Microbiol. 57:316-319.

14. Kondorosi, A. 1991. Overview on genetics of nodule induction: factors controlling nodule induction by Rhizobium meliloti, p. 111-118. In H. Hennecke and D. P. S. Verma (ed.), Advances in molecular genetics of plant-microbe interactions, vol. 1 . Kluwer Academic Publishers, The Netherlands.

15. Kosslak, R. M., R. Bookland, J. Barkei, H. E. Paaren, and E. R. Appelbaum. 1987. Induction of Bradyrhizobium japonicum common nod genes by isoflavones isolated from Glycine max. Proc. Natl. Acad. Sci. USA 84:7428-7432.

16. Le Strange, K. K., G. L. Bender, M. A. Djordjevic, B. G. Rolfe, and J. W. Redmond. 1990. The Rhizobium strain NGR234 nodD1 gene product responds to activation by the simple phenolic compounds vanillin and isovanillin present in wheat seedling extracts. Mol. Plant-Microbe Interact. 3:214-220.

17. Long, S. R. 1989. Rhizobium-legume nodulation: life together in the underground. Cell 56:203-214.

18. Maxwell, C. A., U. A. Hartwig, C. M. Joseph, and D. A. Phillips. 1989. A chalcone and two related flavonoids released from alfalfa roots induce nod genes of Rhizobium meliloti. Plant Physiol. 91:842-847.

19. Miller, J. H. 1972. Experiments in molecular genetics. Cold Spring Harbor Laboratory, Cold Spring Harbor, N.Y.

20. Nadkarni, D. R., and T. S. Wheeler. 1938. Chalkones, condensation of aromatic aldehydes with resacetophenone. Part II. J. Chem. Soc. 1938:1320-1322.

21. Parniske, M. 1991. Flavonoide als Signal- und Abwehrstoffe in der Glycine/Bradyrhizobium Symbiose. Ph.D. thesis. PhilippsUniversität Marburg, Marburg, Germany.

22. Parniske, M., B. Ahlborn, and D. Werner. 1991. Isoflavonoidinducible resistance to the phytoalexin glyceollin in soybean rhizobia. J. Bacteriol. 173:3432-3439.

23. Peters, N. K., and S. R. Long. 1988. Alfalfa root exudates and compounds which promote or inhibit induction of Rhizobium meliloti nodulation genes. Plant Physiol. 88:396-400.

24. Phillips, D. A. Flavonoids: plant signals to soil microbes. Recent Adv. Phytochem., in press.

25. Porter, P. M., W. L. Banwart, and J. J. Hassett. 1985. HPLC isolation and GC-MS identification of genistein, daidzein, and coumestrol from unhydrolysed soybean root extracts. Environ. Exp. Bot. 25:229-232.

26. Recourt, K., J. Schripsema, J. W. Kijne, A. A. N. van Brussel, and B. J. J. Lugtenberg. 1991. Inoculation of Vicia sativa subsp. nigra roots with Rhizobium leguminosarum biovar viciae results in release of nod gene activating flavanones and chalcones. Plant Mol. Biol. 16:841-852.

27. Recourt, K., A. A. N. van Brussel, J. W. Kijne, J. Schripsema, and B. J. J. Lugtenberg. 1990. Inoculation of Vicia sativa with Rhizobium leguminosarum biovar viciae increases the number of nod gene inducing flavonoids secreted by the roots of the host plant. Presented at the 8th International Congress on Nitrogen Fixation, Knoxville, Tenn., 20 to 26 May 1990.

28. Regensburger, B., and H. Hennecke. 1983. RNA polymerase from Rhizobium japonicum. Arch. Microbiol. 135:103-109.

29. Rolfe, B. G. 1988. Flavones and isoflavones as inducing substances of legume nodulation. BioFactors 1:3-10.

30. Schlaman, H. R. M., H. P. Spaink, R. J. H. Okker, and B. J. J. Lugtenberg. 1989. Subcellular localization of the nodD gene product in Rhizobium leguminosarum. J. Bacteriol. 171:4686-4693.

31. Schmidt, P. E., M. Parniske, and D. Werner. Production of the phytoalexin glyceollin I by soybean roots in response to symbiotic and pathogenic infection. Bot. Acta, in press.

32. Truchet, G., P. Roche, P. Lerouge, J. Vasse, S. Camut, F. de Billy, J.-C. Promé, and J. Dénarié. 1991. Sulphated lipo-oligosaccharide signals of Rhizobium meliloti elicit root nodule organogenesis in alfalfa. Nature (London) 351:670-673.

33. Werner, D., J. Wilcockson, and E. Zimmermann. 1975. Adsorption and selection of rhizobia with ion-exchange papers. Arch. Microbiol. 105:27-32.

34. Wollenweber, E., and V. H. Dietz. 1981. Occurrence and distribution of free flavonoid aglycones in plants. Phytochemistry 20:869-932.

35. Wong, E., P. I. Mortimer, and T. A. Geissman. 1965. Flavonoid constituents of Cicer arietinum. Phytochemistry 4:89-95. 